\title{
Dynamic Outflow Obstruction due to Transient Extensive Left Ventricular Wall Motion Abnormalities Caused by Acute Myocarditis in a Patient With Hypertrophic Cardiomyopathy Reduction in Ventricular Afterload by Disopyramide
}

\author{
Yasuhito Sakai, MD; Yasushi Hayashi, MD; Yoshiaki Tomobuchi, MD; \\ Takuzo Hano, MD*; Ichiro Nishio, MD*
}

\begin{abstract}
A 65-year-old woman was admitted to the coronary care unit because of acute pulmonary edema. Immediate 2dimensional and Doppler echocardiograms revealed extensive left venticular wall motion abnormalities and left ventricular hypertrophy with extreme outflow obstruction. Although an ECG showed ST-segment elevation in the anterolateral leads, a coronary arteriogram revealed normal epicardial arteries. Heart failure was relieved after diminishing the dynamic outflow obstruction with disopyramide administration. An endomyocardial biopsy from the right ventricle on the 8th hospital day showed borderline myocarditis. Wall motion abnormalities gradually normalized within 2 weeks. It is speculated that her pulmonary edema would not have been relieved so readily without the immediate reduction in ventricular afterload by disopyramide. These clinical changes over time were observed with serial echo-Doppler examinations. (Jpn Circ J 1999; 63: 640-643)
\end{abstract}

Key Words: Disopyramide; Hypertrophic cardiomyopathy; Myocarditis

$\mathbf{L}$ eft ventricular (LV) wall motion abnormalities in patients with hypertrophic cardiomyopathy (HCM) are not rare in the clinical setting. However, few cases with transient extensive LV wall motion abnormalities in HCM have been reported. They are speculated to be due to myocardial ischemia ${ }^{1}$ or acute myocarditis? We present a case of acute pulmonary edema with LV wall motion abnormalities due to acute myocarditis in HCM, which caused extreme outflow obstruction that was relieved by disopyramide therapy.

\section{Case Report}

A 65-year-old woman, who was hospitalized for the treatment of esophageal varix due to liver cirrhosis with hepatitis $\mathrm{C}$ virus (HCV), complained of sudden chest pain and dyspnea, and was admitted to the coronary care unit. This was her first such episode and no cardiac disease had been noted previously.

On admission, her blood pressure was $116 / 76 \mathrm{mmHg}$ and heart rate 89 beats/min. There was a grade IV systolic ejection heart murmur. Moist breathing rales were noted in both lungs. An electrocardiogram showed right bundle branch block, ST segment elevation and a pathologic Q wave in the anterolateral leads (Fig 1). Two-dimensional and Doppler echocardiograms revealed LV akinesia of the anteroseptal and anterior segments at the papillary muscle level and all segments below that level, asymmetrical

(Received February 8, 1999; revised manuscript received April 15, 1999; accepted April 26, 1999)

Critical Care Medical Center and *Division of Cardiology, Department of Medicine, Wakayama Medical College, Wakayama, Japan

Mailing address: Yasuhito Sakai, MD, Department of Cardiology, Minami-Wakayama National Hospital, 27-1 Takinai-cho, Tanabe, Wakayama 646-8558, Japan septal hypertrophy, LV outflow obstruction with a pressure gradient of $120 \mathrm{mmHg}$, and severe mitral regurgitation due to the systolic anterior motion of the mitral valve leaflets (Fig 2).

Our initial diagnosis was acute myocardial infarction. Therefore, coronary arteriography was performed immediately; however, the epicardial coronary arteries were entirely normal. A left ventriculogram from the right anterior oblique projection view showed extensive akinetic anterolateral, apical, and diaphragmatic segments compatible with those observed on the echocardiogram. Other segments were hyperkinetic (Fig 3). The LV pressure curve revealed a pressure gradient of $90 \mathrm{mmHg}$ between the apex and the outflow tract with a markedly high LV end-diastolic pressure of $40 \mathrm{mmHg}$. A Swan-Ganz catheter inserted from the femoral vein showed that the cardiac index was $2.3 \mathrm{~L} \mathrm{~min}^{-1} \mathrm{~m}^{-2}$ by thermodilution and the pulmonary capillary wedge pressure was $22 \mathrm{mmHg}$.

Intravenous administration of $25 \mathrm{mg}$ of disopyramide decreased the pressure gradient from 120 to $60 \mathrm{mmHg}$ on the continuous-wave Doppler echocardiogram and increased the systolic blood pressure from 85 to 120 $\mathrm{mmHg}$. Therefore, oral disopyramide therapy was begun at a daily dose of $300 \mathrm{mg}$. We also administered furosemide intravenously during the monitoring of right atrial pressure. Vasodilators and inotropes were not given because of the dynamic outflow obstruction. Her chest pain and dyspnea were relieved gradually. The pulmonary capillary wedge pressure was reduced to $10 \mathrm{mmHg}$ on the next day. On that same day, a $99 \mathrm{mTc}$ tetrofosmin scintigram performed by single photon emission computed tomography (SPECT) imaging showed a perfusion defect of the area compatible with that of the akinesia seen on the left ventriculogram and echocardiogram. With regard to laboratory data, the white blood cell count and creatine kinase value did not 

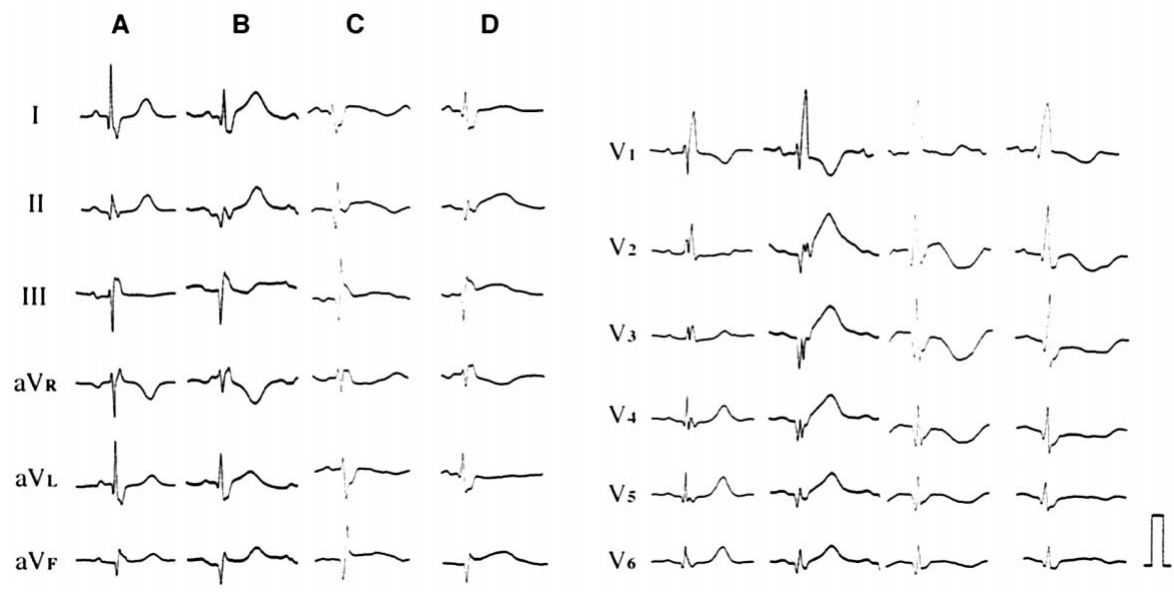

Fig 1. Serial electrocardiographic tracings. In the second tracing, there is an ST segment elevation in leads I, $\mathrm{a} V_{\mathrm{L}}$, and $\mathrm{V}_{2-6}$. In the third and fourth tracings, however, there is resolution of the ST-segment elevation, T-wave inversion, and an increase in the Rwave voltage in these leads. (A) control, (B) 1st day, (C) 3rd day, (D) 6th day.
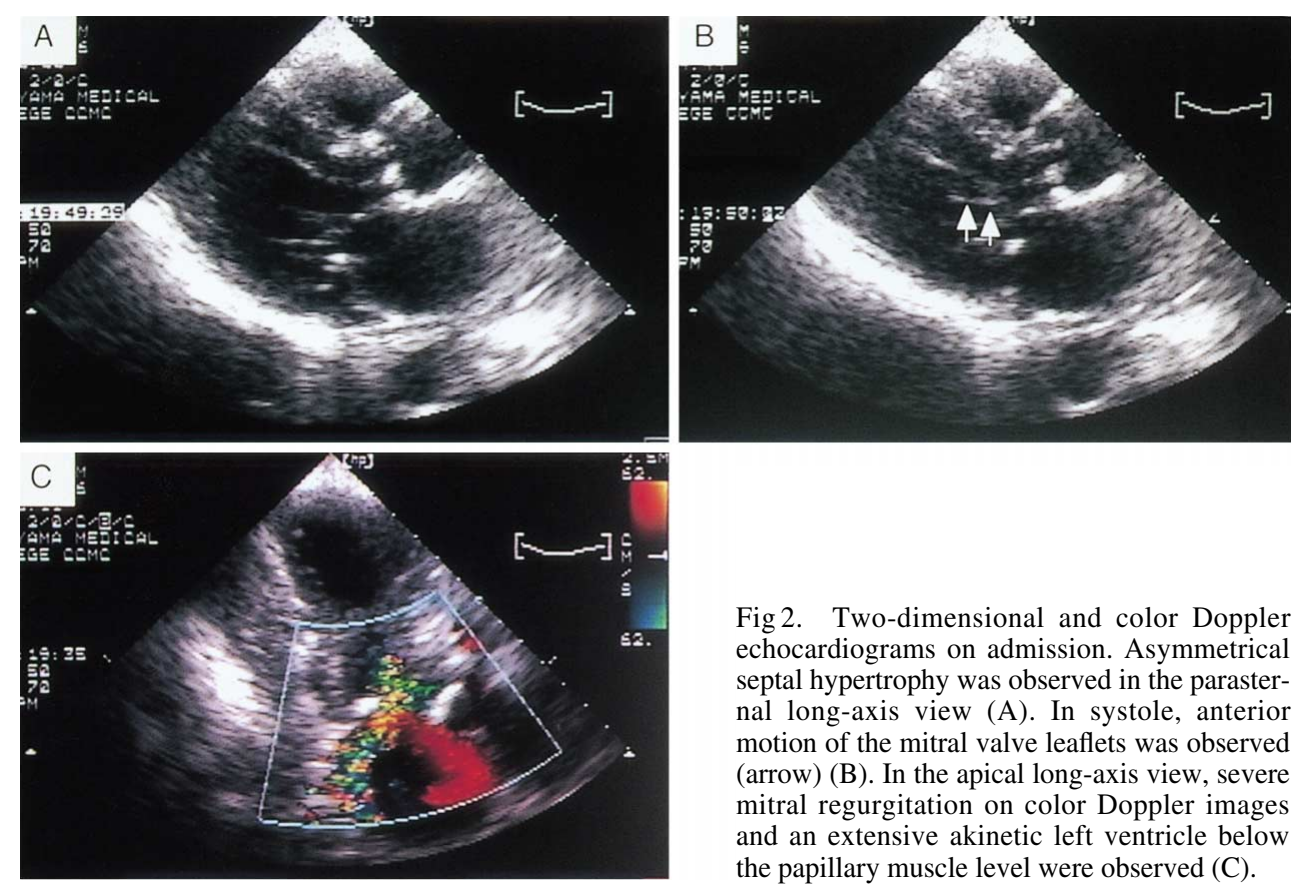

Fig 2. Two-dimensional and color Doppler echocardiograms on admission. Asymmetrical septal hypertrophy was observed in the parasternal long-axis view (A). In systole, anterior motion of the mitral valve leaflets was observed (arrow) (B). In the apical long-axis view, severe mitral regurgitation on color Doppler images and an extensive akinetic left ventricle below the papillary muscle level were observed (C).

show a significant rise. The peak serum levels of C-reactive protein and troponin- $\mathrm{T}$ were $81.1 \mathrm{mg} / \mathrm{L}$ and $2.21 \mu \mathrm{g} / \mathrm{L}$, respectively, which suggested some myocardial damage.

A repeat echocardiogram performed on Day 4 revealed the absence of significant outflow tract obstruction without systolic anterior motion of the mitral valve leaflets and slight improvement of the anterior wall motion, changes that had not been observed on the 2nd hospital day (Fig 4). Serial electrocardiograms showed resolution of the STsegment elevation, $T$ wave inversion, and recovery of $R$ wave voltage in the anterolateral leads (Fig 1).

When the dosage of disopyramide was decreased to 150 $\mathrm{mg} / \mathrm{day}$ from the 6th day onward because of marked prolongation of the QT interval on electrocardiogram, the systolic ejection murmur re-emerged and Doppler examination revealed significant outflow obstruction (pressure gradient: $110 \mathrm{mmHg}$ ) on the next day. Therefore, the dosage of disopyramide was doubled immediately. A follow-up echocardiogram on Day 8 showed LV asynergy only in the apical segment and no significant outflow obstruction (Fig 4). The cardiac index increased to 2.9 $\mathrm{L} \mathrm{min}^{-1} \mathrm{~m}^{-2}$. On the same day, the patient underwent endomyocardial biopsy from the right ventricle. Histology showed interstitial lymphocytic infiltrates and interstitial edema without myocardial necrosis. She was discharged from the coronary care unit the next day. An echocardiogram performed on Day 15 showed no LV wall motion abnormalities (Fig 4). A repeat $99 \mathrm{mTc}$ tetrofosmin scintigram performed 1 month after the first examination demonstrated no perfusion defect and no LV wall motion abnormalities, with an ejection fraction of $60 \%$. At the last follow-up, which was 4 months after the event, the patient was symptom-free. An echocardiogram also showed no wall motion abnormalities and no significant outflow obstruction despite unchanged septal hypertrophy.

\section{Discussion}

Although the symptom of chest pain, the ST segment elevation in the anterolateral leads on electrocardiogram and the wall motion abnormalities on echocardiogram resulted in an initial diagnosis of acute myocardial infarction, the coronary arteriogram revealed entirely normal epicardial coronary arteries. Myocardial ischemia with 

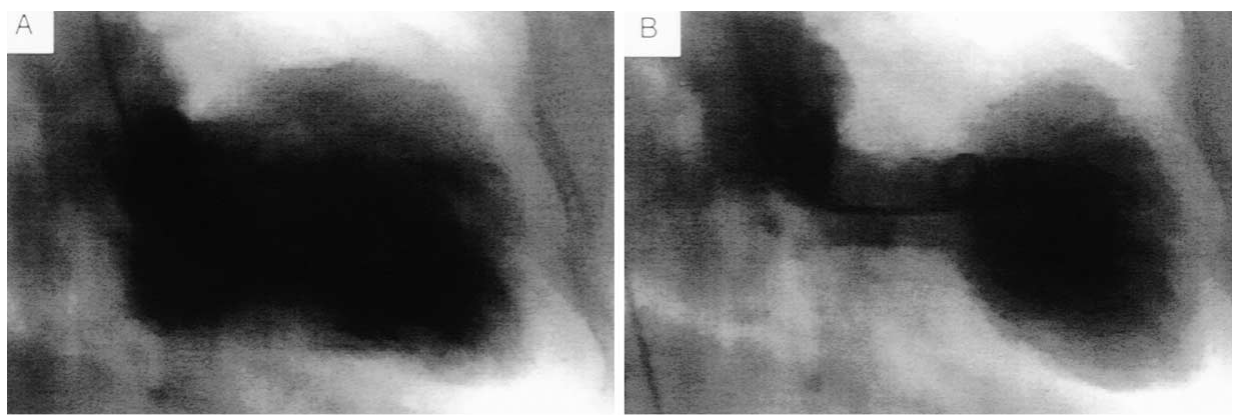

Fig 3. Left ventriculograms demonstrating extensive akinesia of anterolateral, apical, and diaphragmatic segments with hyperkinesia of other segments. (A) Diastole, (B) systole.

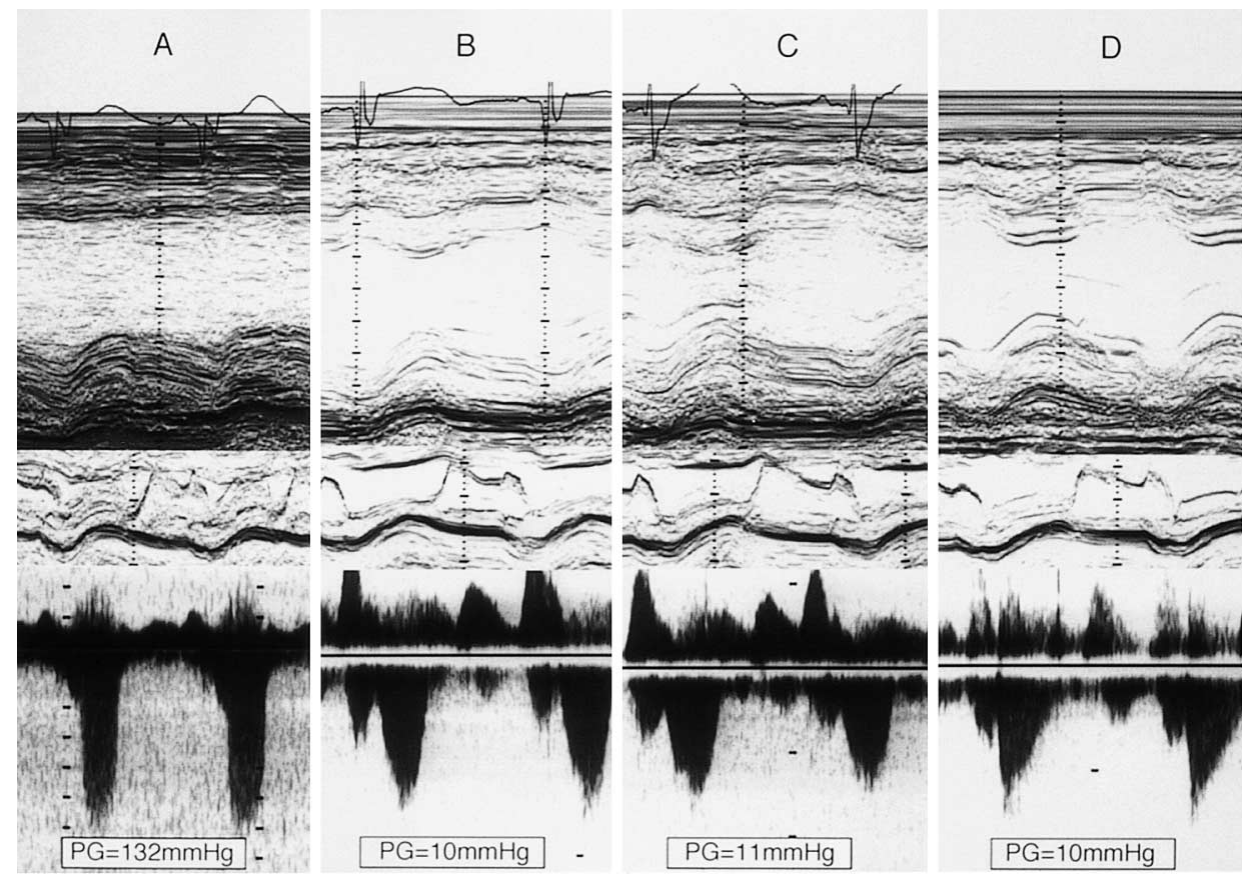

Fig 4. Serial 2-dimensional M-mode echocardiographic tracings of the left ventricle (top) and mitral leaflets (center) and continuous-wave Doppler tracings of the outflow tract (bottom). Anterior wall motion recovered gradually. Dynamic outflow tract obstruction markedly diminished with the vanishing of the systolic anterior motion of the mitral valve leaflets. (A) 2nd day, (B) 4th day, (C) 8th day, (D) 15th day. PG, pressure gradient.

normal epicardial coronary arteries in HCM is not rare. A variety of mechanisms have been considered, which at least in part result from an imbalance between oxygen supply and demand as a consequence of the greatly increased muscle mass? However, transient LV asynergy has been reported only by Fine et $\mathrm{al}^{1}$ in a case with stunned myocardium. Vasospasm or microvascular disease also remains a possibility. In the present patient, however, the area of LV asynergy was more extensive than the territory of her left anterior descending coronary artery. Therefore, coronary artery disease was unlikely to be the mechanism of this patient's wall motion abnormalities although a provocation test for coronary artery spasm was not performed.

Myocarditis can mimic myocardial infarction ${ }^{4,5}$ or cause ventricular aneurysm2,6 At first, myocarditis was not considered in the present patient due to the absence of signs of infection and the lack of a significant rise in cardiac enzyme values. However, endomyocardial biopsy revealed 'borderline' myocarditis based on the Dallas criteria? Dec et al reported that two-thirds of repeat samplings revealed myocarditis after 'borderline' myocarditis was shown at the initial sampling; ${ }^{8}$ however, a definite diagnosis was not made in the present case because the patient refused subsequent sampling. Moreover, the serial electrocardiographic and echocardiographic findings suggest myocarditis as the most likely cause of this event. Some Japanese investigators ${ }^{9,10}$ have reported such transient $\mathrm{LV}$ wall motion abnormalities without HCM due to various causes, ${ }^{11,12}$ such as 'takotsubo (a pot for catching octopuses)'-like cardiomyopathy for the LV shape at end-systole. Myocarditis is also suggested to be a cause.10

$99 \mathrm{~m}$ Tc-labeled tetrofosmin is a recently developed myocardial perfusion agent that overcomes the limitations of ${ }^{201} \mathrm{Tl}^{13}$ Myocarditis may produce perfusion defects on ${ }^{201} \mathrm{Tl}$ imaging! 14 The present patient showed an extensive perfusion defect in the acute phase, but the defect was completely resolved in a follow-up study using $99 \mathrm{mTc}$ tetrofosmin SPECT imaging. Although these scintigraphic findings may suggest acute myocarditis as the cause, its diag- 
nostic value remains obscure.

Recently, Matsumori et al reported a link between HCM and HCV infection and speculated that HCV infection may play a role in the development of HCM 15 Moreover, they presented cases in which HCV infection caused myocarditis and the development of HCM. The present patient had HCV infection and was diagnosed as having liver cirrhosis. Although cardiac disease had not been noted before this episode, persistent infection may have caused the marked LV hypertrophy. The reversibility of LV wall motion abnormalities and acute left heart failure with chest pain in this patient suggest acute myocarditis. However, we cannot deny the possibility of latent chronic myocarditis from $\mathrm{HCV}$ infection as the cause of wall motion abnormalities because the causative virus was not determined, and the endomyocardial biopsy specimen revealed mild inflammation.

In addition to the extensive LV injury, severe LV outflow obstruction in this patient complicated the hemodynamics. Decreasing the pressure gradient of the outflow tract has an important role in the treatment of such patients, which reduces ventricular afterload and relieves myocardial ischemia. Beta-blockade and verapamil have been used for this purpose because they have a negative inotropic effect. Pollick et al demonstrated that disopyramide, a class Ia antiarrhythmic agent with a negative inotropic effect, is more effective than these other agents in decreasing the outflow pressure gradient and lessening symptoms ${ }^{16,17}$ Improvement of $\mathrm{LV}$ diastolic function also has been reported in HCM with outflow obstruction, but not in patients without obstruction ${ }^{18}$ In the case reported here, intravenous and oral disopyramide was extremely effective in diminishing dynamic outflow obstruction. We speculate that the patient's pulmonary congestion would not have been relieved so readily without the immediate reduction in ventricular afterload by disopyramide.

To our knowledge, this is the first report of acute heart failure with transient extensive LV motion abnormalities due to myocarditis in HCM with LV outflow obstruction, which was relieved after diminishing the dynamic outflow obstruction with disopyramide. These clinical changes over time were observed with serial echo-Doppler examinations.

\section{References}

1. Fine DG, Clements IP, Callahan MJ: Myocardial stunning in hypertrophic cardiomyopathy: recovery predicted by single photon emission computed tomographic thallium-201 scintigraphy. J Am Coll
Cardiol 1989; 13: 1415-1418

2. Fisher DZ, DiSalvo TG, Dec GW, DeSanctis RW: Transient left ventricular aneurysm in a patient with hypertrophic cardiomyopathy and myocarditis. Clin Cardiol 1993; 16: 253-256

3. Wynne J, Braunwald E: The cardiomyopathies and myocarditis. In: Braunwald E, editor. Heart disease: A textbook of cardiovascular medicine, 5th edn. Philadelphia: WB Saunders, 1997: 1404-1463

4. Dec GW, Waldman H, Southern J, Fallon JT, Hutter AM, Palacios I: Viral myocarditis mimicking acute myocardial infarction. J Am Coll Cardiol 1992; 20: 85-89

5. Narula J, Khaw BA, Dec GW, Palacios IF, Southern JF, Fallon JT, et al: Recognition of acute myocarditis masquerading as acute myocardial infarction. N Engl J Med 1993; 328: 100-104

6. Frustaci A, Maseri A: Localized left ventricular aneurysms with normal global function caused by myocarditis. Am J Cardiol 1992; 70: $1221-1224$

7. Aretz H, Billingham M, Edwards W, Factor S, Fallon J, Fenoglio J et al: Myocarditis: A histopathologic definition and classification. Am J Cardiovasc Pathol 1986; 1: 3-14

8. Dec GW, Fallon J, Southern J, Palacious I: 'Borderline' myocarditis An indication for repeat endomyocardial biopsy. J Am Coll Cardiol 1990; 15: 283-289

9. Ishihara M, Sato H, Tateishi H, Kawagoe T, Shimatani Y, Nakagawa K, et al: 'Takotsubo'-like cardiomyopathy. Kokyu to Junnkan 1997; 45: $879-885$

10. Kawakami H, Matsuoka H, Koyama Y, Saeki H, Itoh T: A case of 'takotsubo' like cardiomyopathy due to acute myocarditis. Kokyu to Junnkan 1998; 46: 913-917

11. Yamanaka O, Yasumasa F, Nakamura T, Ohno A, Endo Y, Yoshimi $\mathrm{K}$, et al: 'Myocardial stunning'-like phenomenon during a crisis of pheochromocytoma. Jpn Circ J 1994; 58: 737-742

12. Iga K, Himura Y, Izumi C, Miyamoto T, Kijima K, Gen H, et al Reversible left ventricular dysfunction associated with GuillainBarre syndrome: An expression of catecholamine cardiotoxicity? Jpn Circ J 1995; 59: 236-240

13. Tamaki N, Yonekura Y, Kadota K, Kambara H, Torizuka K: Thallium-201 myocardial perfusion imaging in myocarditis. Clin Nucl Med 1985; 10: 562-566

14. Tamaki N, Takahashi N, Kawamoto M, Torizuka K, Tadamura E, Yonekura Y, et al: Myocardial tomography using technetium-99mtetrofosmin to evaluate coronary artery disease. J Nucl Med 1994; 35: $594-600$

15. Matsumori A, Matoba Y, Nishio R, Shioi T, Ono K, Sasayama S Detection of hepatitis $C$ virus RNA from the heart of patients with hypertrophic cardiomyopathy. Biochem Biophys Res Commun 1996; 222: $678-682$

16. Pollick C, Kimball B, Henderson M, Wigle ED: Disopyramide in hypertrophic cardiomyopathy. I. Hemodynamic assessment after intravenous administration. Am J Cardiol 1988; 62: 1248-1251

17. Pollick C: Disopyramide in hypertrophic cardiomyopathy. II. Noninvasive assessment after oral administration. Am J Cardiol 1988; 62: $1252-1255$

18. Matsubara H, Nakatani S, Nagata S, Ishikura F, Katagiri Y, Ohe T, et al: Salutary effect of disopyramide on left ventricular diastolic function in hypertrophic obstructive cardiomyopathy. $\mathrm{J} \mathrm{Am} \mathrm{Coll} \mathrm{Cardiol}$ 1995; 26: $768-775$ 